\title{
Analytical Model for the Flow in Progressing Cavity Pump with the Metallic Stator and Rotor in Clearance Fit
}

\author{
Lei Zheng $\mathbb{D}^{1}{ }^{1}$ Xiaodong Wu, ${ }^{1}$ Guoqing Han, ${ }^{1}$ Huachang Li, $^{2}$ Yi Zuo, ${ }^{1}$ and Dake Zhou \\ ${ }^{1}$ MOE Key Laboratory of Petroleum Engineering, China University of Petroleum-Beijing, Beijing 102249, China \\ ${ }^{2}$ Sinopec International Petroleum Service Corporation, Beijing 100020, China
}

Correspondence should be addressed to Lei Zheng; sydxzhenglei@163.com

Received 9 April 2018; Accepted 25 June 2018; Published 24 July 2018

Academic Editor: Nicolas Gourdain

Copyright (C) 2018 Lei Zheng et al. This is an open access article distributed under the Creative Commons Attribution License, which permits unrestricted use, distribution, and reproduction in any medium, provided the original work is properly cited.

\begin{abstract}
As the metallic stator progressing cavity pump (PCP) operates with the stator and rotor in clearance fit, the slippage between cavities has a significant influence on the pump performance. In this paper, an analytical model is developed for the flow in the metallic stator PCP. Based on the analyses of the meshing movement and the clearance geometry inside the pump, the slippage through the transversal and longitudinal sealing regions is calculated considering different slippage mechanisms. Then the flow rate is obtained by subtracting the total slippage from the theoretical volumetric rate. This model is validated against results obtained from the performance experiments of commercial metallic stator PCP products from Shihong Petroleum Equipment Company. The model results show that the metallic stator PCP with smaller clearance or more stages is more capable of achieving good performance at high differential pressure. It is suitable for pumping the fluid with certain viscosity, and the influence of the slippage can be compensated by adopting appropriate high rotational speed. Furthermore, the model can be used to predict the pump performance and provide guidance for the pump design and performance optimization in field applications.
\end{abstract}

\section{Introduction}

Progressing cavity pump (PCP) is a positive displacement pump devised by Moineau in the 1930s [1], which has been used for the artificial lift to enhance oil production in the oilfield since the 1970s [2, 3]. For the operation of the conventional PCP, a helical rotor rotates eccentrically inside a helical stator with interference between them, in which the stator is generally deformable and made of elastomeric material. It has many benefits in oilfield applications, such as simple installation, easy operation, low flow pulsation, high efficiency, and high tolerance for gas and solid contents. Most importantly, it shows a good adaptability for pumping the fluid with high viscosity, which makes it widely used in viscous oil fields [4-6]. However, due to the characteristics of the elastomeric stator and the interference fit, the conventional PCP has some shortcomings in temperature resistance $\left(<160^{\circ} \mathrm{C}\right)$ and abrasion resistance [7], which limits its application in oilfield, especially in thermal production wells. Therefore, the PCP with the metallic stator and rotor, also known as all metal PCP, becomes recognized as an alternative artificial lift method for both the cold and thermal production $[8,9]$. It is applicable to a larger range of temperature almost up to $350^{\circ} \mathrm{C}$, due to the high temperature tolerance of the metallic stator. To relieve the mechanical friction inside the pump, the metallic stator PCP operates with a small clearance between the stator and rotor, as shown in Figure 1. In comparison with the conventional PCP, the metallic stator PCP not only inherits the traditional advantages and breaks temperature limitation but also reduces the reaction torque between the stator and rotor caused by the conventional interference fit and the elastomer swelling. The metallic stator PCP has been applied in many field cases in recent decades [10-13], which is proved to be an effective and promising artificial lift technology for oil production.

Fundamental understanding of the PCP performance can provide scientific basis for the pump application in the artificial lift system, which is significant for oilfield engineers $[14,15]$. However, the PCP performance curves provided by manufacturers are insufficient to directly represent the real flow rate under actual downhole conditions. The realistic PCP performance is mainly determined by the relationship 


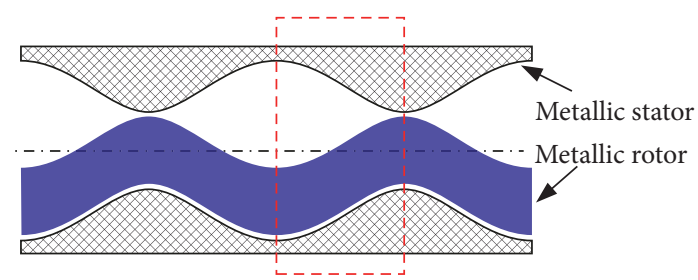

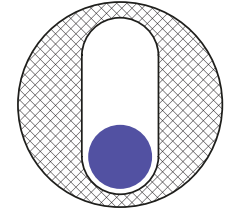

Left view

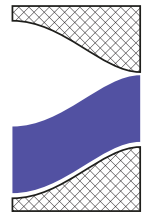

Front view

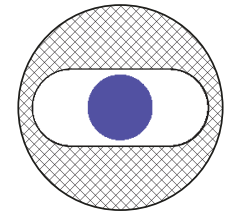

Right view
FIgURe 1: Schematic of metallic stator PCP in clearance fit.

between the pumping flow and different parameters related to the PCP geometry, fluid property, and actual operation. This is also the main reason behind many studies focusing on the flow inside PCPs.

In order to study the performance of the metallic stator PCP in clearance fit, researchers have proposed some numerical models by the computational fluid dynamics (CFD) software and the finite element methods (FEM) [16-21]. Though these models are usually of high fidelity to analyze the flow inside the pump, they are often computationally expensive and impractical to provide direct instructions for the actual pump applications. As there are usually plenty of pumps with different geometries operating under various conditions in the oilfield, there can be a lot of complex works to establish numerical models for the performance of all pumps.

As is known to all, for the purpose of guiding the pump applications, it is important to make the model simple and efficient to be an engineering tool. By contrast, the analytical models stand out to be more feasible to be used for quantitative analysis of the flow in the metallic stator PCP. Olivet et al. [22] and Gamboa et al. [23] had performed extensive experiments to study the performance of a metallic stator PCP prototype, and the transient pressure profiles along consecutive cavities were also obtained. Based on the experimental study, Gamboa et al. [24] made the first attempt to propose an analytical model for the flow, in which the slippage was the result of two components due to the differential pressure and the rotor movement. However, a definitive model still needs to be established by further studies on the calculation of the friction factor and the clearance geometry between the stator and rotor. For the same reason, Paladino et al. [16] failed to analyze the pump performance with reference to Gamboa's method, so they had to turn to a numerical model implemented by the software of ANSYS. Pessoa et al. [25] in the same research team tried once again to develop a simplified analytical model for the flow. To avoid the previous problems, they obtained the slippage channel lengths simply from the results of their numerical models [16, 17]. However, it is remarkable that the slippage channel dimensions are only for the specific metallic stator PCP prototype in Gamboa's experiments, which cannot represent any other actual pumps with different structures. Nguyen et al. [26] developed another analytical model to simulate the actual flow rate, based on their previous analytical model for the theoretical flow [27]. But the same computational problem of the slippage channels existed in the proposed model, in which they borrowed the slippage channel lengths from Pessoa et al. [25]. Therefore, at least in literature review, the geometry of slippage channels or clearance inside the pump is still not well clarified. The related calculation is challenging due to the complex PCP structure, but it is necessary for the model development. In addition, Pessoa et al. [25] and Nguyen et al. [26] only considered the effect of the slippage component due to the differential pressure, ignoring the other slippage component due to the relative motion between the rotor and stator.

In view of these, there is still a lack of a rigorous and comprehensive analytical approach to effectively model the flow in the metallic stator PCP in clearance fit. The objective of this paper is to develop an analytical model that can predict the flow more rigorously and comprehensively compared with existing analytical models. The new model is implemented on the basis of the accurate calculation of the slippage between cavities by considering different slippage mechanisms and modeling relevant slippage channels in transversal and longitudinal directions. It can be used to study the effects of geometrical and operating parameters on the pump performance. The model is also significant to predict the pump performance and provide guidance for the pump design and performance optimization in field applications.

\section{Performance analysis of Metallic Stator PCP}

2.1. Theoretical Volumetric Rate. For the metallic stator PCP, the clearance fit between the stator and rotor is characterized by the specific geometry that the stator diameter is bigger than the rotor diameter. The distance between the stator and rotor is positive, given as

$$
\delta=\frac{d_{\mathrm{s}}-d_{\mathrm{r}}}{2}
$$

where $\delta$ is the fit clearance, $\mathrm{m} ; d_{\mathrm{s}}$ is the stator diameter, $\mathrm{m} ; d_{\mathrm{r}}$ is the rotor diameter, $\mathrm{m}$.

Considering the influence of the positive clearance on the flow, the cross-sectional area of the flow inside the metallic stator PCP is a little bigger than that of the conventional PCP in interference fit with the same geometry, which can be calculated as [23]

$$
A=4 e d_{\mathrm{r}}+8 e \delta+\pi\left(\delta d_{\mathrm{r}}+\delta^{2}\right)
$$

where $A$ is the cross-sectional area of the flow, $\mathrm{m}^{2} ; e$ is the rotor eccentricity, $\mathrm{m}$.

Due to the aforementioned structure characteristics, the theoretical volumetric rate of the metallic stator PCP cannot be precisely calculated by simply using the traditional method. However, among the basic parameters on the product label of the metallic stator PCP, the single-rotation 


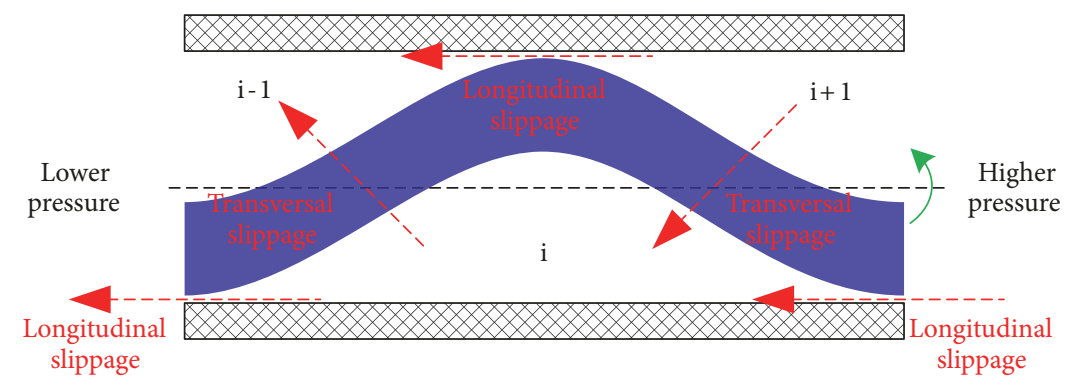

FIgURE 2: Slippage flow in the clearance between the stator and rotor.

theoretical volumetric rate still refers to the conventional formula $q_{\mathrm{r}}=4 e d_{\mathrm{r}} T$. It is defined as a geometrical parameter ignoring the distance between the stator and rotor in different fit modes. Therefore, the single-rotation theoretical rate $q_{\mathrm{r}}$ in clearance fit needs to be modified in consideration of the real flow sectional area as (2). Then the theoretical volumetric rate of the metallic stator PCP can be obtained by multiplying the modified $q_{\mathrm{r}}$ by the rotational speed, given as

$$
\begin{aligned}
Q_{\mathrm{t}} & =1440(1+\alpha) q_{\mathrm{r}} n \\
\alpha & =\frac{8 e \delta+\pi\left(\delta d_{\mathrm{r}}+\delta^{2}\right)}{4 e d_{\mathrm{r}}}
\end{aligned}
$$

where $Q_{t}$ is the theoretical volumetric rate of the metallic stator PCP, $\mathrm{m}^{3} / \mathrm{d} ; \alpha$ is the correction factor considering the influence of the clearance, dimensionless; $q_{\mathrm{r}}$ is the singlerotation theoretical rate ignoring the distance between the stator and rotor, $\mathrm{m}^{3} / \mathrm{r} ; n$ is the rotational speed, $\mathrm{r} / \mathrm{min} ; T$ is the stator pitch, $\mathrm{m}$.

2.2. Operating Mechanism with Slippage. Similar to the conventional PCP, the pump body of the metallic stator PCP is divided into several cavities by sealing lines formed by mutual meshing movement between the stator and rotor. When the rotor rotates during pump operating, the fluid within each cavity moves spirally from the inlet cavity to the outlet cavity, continuously being pressurized and artificially lifted. However, due to different characteristics of the clearance fit and the interference fit between the stator and rotor, the operating mechanism of the metallic stator PCP is different from that of the conventional PCP. For PCP operating in interference fit, cavities can be well sealed and little slippage occurs at normal lifting pressure, in which the flow rate is approximately equal to the theoretical volumetric rate. And only when the deformation of the elastomer stator under high pressure exceeds the interference, the slippage between cavities occurs. For the metallic stator PCP in clearance fit, cavities in different stages along the pump are connected with each other, and slippage flow occurs in the clearance between them, as illustrated in Figure 2. Meanwhile, it needs to be noted that the pumping fluid (usually viscous oil) has a certain viscosity, and the fit clearance is much smaller than the pump structure size. The viscous drag of the fluid has a certain sealing effect on the slippage flow in the clearance between the stator and rotor, which can ensure the pumping capacity of the PCP operating in clearance fit. In other words, the metallic stator PCP operates with slippage flow more or less through the sealing lines between cavities, which is governed by a balance between the pressure difference and viscous forces.

According to the structure and meshing characteristics of the stator and rotor, the slippage flow generally occurs through the sealing lines in two directions, including the transversal slippage between the adjacent cavities and the longitudinal slippage between the spaced cavities. For the fluid in the specific cavity $i$, it experiences the slippage inflow from the higher pressure cavities and the slippage outflow to the lower pressure cavities at the same time. More specifically, the inflow includes the transversal slippage from the cavity $i+1$ and the longitudinal slippage from the cavity $i+2$, while the outflow includes the transversal slippage to the cavity i-1 and the longitudinal slippage to the cavity $\mathrm{i}-2$. The integrated slippage happens between the consecutive cavities inside the metallic stator PCP and has a significant effect on the pump performance in the process of artificial lifting.

Referring to the principles of positive displacement pumps, the performance of the metallic stator PCP is a function of the theoretical volumetric rate and the slippage. As previously mentioned in (3), the theoretical volumetric rate at given rotational speed simply depends on the pump geometry. Therefore, the essential issue of predicting the actual flow rate is to calculate the slippage under the clearance fit condition between the stator and rotor. Due to the complexity of the slippage mechanisms and the sealing lines between cavities, the analytical calculation of total slippage inside the metallic stator PCP is certainly challenging. It needs to be mentioned that the slippage is a combined effect of several factors, including the pump geometry, the fluid property, the rotor kinematics, and the differential pressure.

\section{Mathematical Modeling}

3.1. Calculation Method of Slippage. For the metallic stator PCP operating in clearance fit, the clearance structures between cavities are also known as the sealing regions. As the clearance dimension is much smaller than the diameter of the stator and rotor, the hydraulic diameter of the internal clearance is small. In addition, as the pumping fluid is generally viscous in the oil production, the Reynolds number is relatively small. Therefore, the slippage flow through the sealing clearance can be regarded as laminar flow, ignoring 


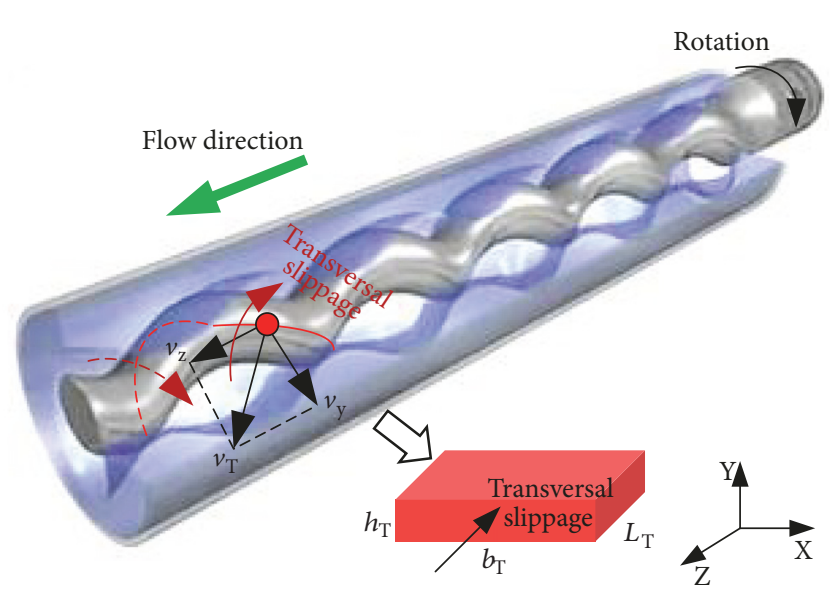

(a) Transversal slippage

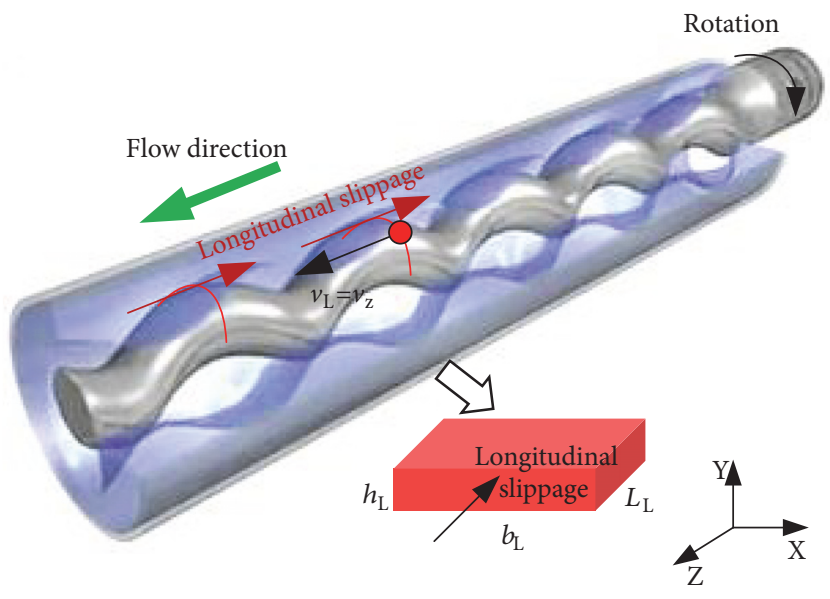

(b) Longitudinal slippage

FIGURE 3: Slippage models for sealing regions in different directions.

the turbulence effect. Based on the previous studies on the liquid slippage flow through the sealing clearance [28], the slippage can be obtained as a result of two components, one due to the differential pressure between cavities and the other due to the relative motion between the stator and rotor, given as follows:

$$
\begin{aligned}
q & =q_{\mathrm{p}}+q_{\mathrm{v}} \\
q_{\mathrm{p}} & =\frac{b h^{3}}{12 \mu L} \Delta P_{\mathrm{s}} \\
q_{\mathrm{v}} & =\frac{b h}{2} v
\end{aligned}
$$

where $q$ is the total liquid slippage, $\mathrm{m}^{3} / \mathrm{s} ; q_{\mathrm{p}}$ is the slippage due to the differential pressure, $\mathrm{m}^{3} / \mathrm{s} ; q_{\mathrm{v}}$ is the slippage due to the relative motion, $\mathrm{m}^{3} / \mathrm{s} ; h$ is the height of the sealing region, $\mathrm{m}$; $b$ is the width of the sealing region, $\mathrm{m} ; L$ is the length of the sealing region, $\mathrm{m} ; \Delta P_{\mathrm{s}}$ is the differential pressure, $\mathrm{Pa} ; \mu$ is the fluid viscosity, Pa.s; $v$ is the relative velocity, $\mathrm{m} / \mathrm{s}$.

Combining different slippage directions illustrated in Figure 2, the slippage model can be extended for the metallic stator PCP operating in clearance fit to study the transversal slippage and longitudinal slippage between cavities, as shown in Figure 3. The sealing regions between cavities in different directions are assumed to be two cubic slippage channels depending on the pump geometry.

Note that the pressure inside the pump increases linearly from the inlet cavity to the outlet cavity during pump operation [22, 23]; thus the single-stage pressure difference $\Delta P$ can be calculated by dividing the total lifting pressure $\Delta P_{\mathrm{p}}$ by the number of pump stages $N$, expressed as $\Delta P=\Delta P_{\mathrm{p}} / N$. As is known that there are two cavities for one stator pitch, the longitudinal differential pressure between spaced cavities is equal to $\Delta P$, while the transversal differential pressure between adjacent cavities is $0.5 \Delta P$.

In Figure 3, different parameters of the sealing regions in different directions are given referring to the basic model, such as geometric dimensions $(b, L, h)$ and velocity components $\left(v_{\mathrm{x}}, v_{\mathrm{y}}, v_{\mathrm{z}}\right)$, in which two subscripts $\mathrm{T}$ and $\mathrm{L}$ represent the transversal direction and longitudinal direction respectively. The velocity components can be obtained on the basis of the meshing movement between the stator and rotor, while the calculation of geometric dimensions needs to take into account both the clearance structure and the fluid dynamics lubrication conditions between cavities. The related details will be analyzed in the following.

3.2. Meshing Movement between the Stator and Rotor. According to the operating principles of PCP, the meshing movement between the stator and rotor mainly consists of two types of motions, including the point meshing and the line meshing, which forms continuous meshing lines along the clearance structures. These meshing lines also play as sealing lines between cavities during the PCP operating in clearance fit. The transversal slippage flows through the sealing lines formed at straight sections of the stator, while the longitudinal slippage flows through the sealing lines at fixed positions corresponding to semicircular sections of the stator [24]. Figure 4 shows the two-dimensional coordinate system of the pump cross-section, in which the center of the stator is the origin. Based on the meshing laws between the stator and rotor, the meshing velocity of each point on the sealing lines can be calculated [29].

On the sealing lines of the transversal slippage, the point meshing exists at the positions as shown in Figure 4(a). The meshing velocity of each point varies periodically with the rotor rotation, which can be calculated as

$$
\begin{aligned}
v_{\mathrm{x}}(t) & =0 \\
v_{\mathrm{y}}(t) & = \begin{cases}-v_{\mathrm{y}_{1}}-v_{\mathrm{y} 2}(t), & \text { line } \mathrm{CD} \\
v_{\mathrm{y} 1}-v_{\mathrm{y} 2}(t), & \text { line AF }\end{cases} \\
v_{\mathrm{y} 1} & =\frac{\pi n}{60} d_{\mathrm{r}}
\end{aligned}
$$




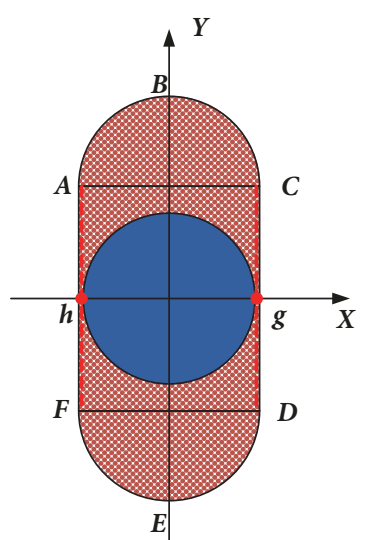

(a) Point meshing for transversal sealing

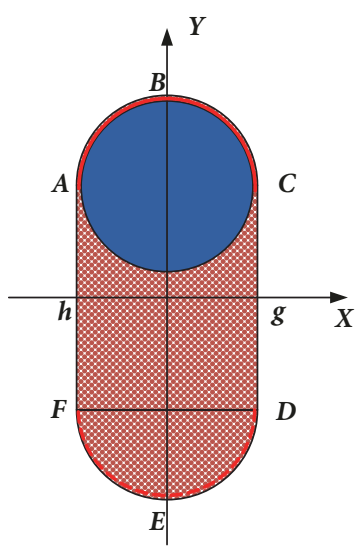

(b) Line meshing for longitudinal sealing
FIgURE 4: Meshing between the stator and rotor.

$$
\nu_{\mathrm{y} 2}(t)=\frac{\pi n e}{15} \sin \frac{\pi n t}{30}
$$

where $v_{\mathrm{x}}(t)$ and $v_{\mathrm{y}}(t)$ are the velocity components of the meshing points on the straight sections (represented as the lines $\mathrm{CD}$ and $\mathrm{AF}$ ), respectively, in $\mathrm{X}$ and $\mathrm{Y}$ directions at different time, $\mathrm{m} / \mathrm{s} ; v_{\mathrm{y} 1}$ and $v_{\mathrm{y} 2}(t)$ are the velocities in $\mathrm{Y}$ direction, respectively, depending on the rotor rotation and the rotor reciprocating motion, $\mathrm{m} / \mathrm{s}$; $t$ is the time, $\mathrm{s}$.

On the sealing lines of the longitudinal slippage, the line meshing exists at the positions as shown in Figure 4(b). Every meshing point rotates along the semicircle section of the stator (represented as the arcs $\mathrm{ABC}$ and $\mathrm{DEF}$ ), so the resultant velocity can be obtained as

$$
v_{\mathrm{xy}}= \begin{cases}\frac{\pi n d_{\mathrm{r}}}{60}, & \operatorname{arc~ABC} \\ -\frac{\pi n d_{\mathrm{r}}}{60}, & \text { arc DEF }\end{cases}
$$

where $v_{\mathrm{xy}}$ is the resultant velocity of line meshing in the $\mathrm{XY}$ plane, $\mathrm{m} / \mathrm{s}$.

The above analyses mainly focus on the velocities of the meshing positions based on the pump cross-section (XY plane). It should be noted that every meshing point also has an axial velocity along the pump transmission direction, given as

$$
v_{\mathrm{z}}=\frac{n T}{60}
$$

where $v_{\mathrm{z}}$ is the axial velocity of each meshing point, $\mathrm{m} / \mathrm{s}$.

3.3. Clearance Geometry between Consecutive Cavities. Due to the complex profiles of the stator and rotor and the relative motion between them, it is challenging to accurately calculate the geometric dimensions of sealing regions between cavities, also known as the internal clearance where the slippage happens. Therefore, for the rigid PCP with metallic stator and rotor, the lubrication theory about the geometric calculation of the oil film structure in small clearances $[30,31]$ is introduced to analyze the geometric dimensions of sealing regions. The detailed derivation is provided in Appendix, and related analyses are based on the meshing between the stator and rotor. For the quantitative analysis of the sealing regions, it is assumed that there is no contact collision between the rotor and stator during the rotor rotation, and the distance between them in each meshing position is uniform along the pump body and can be viewed as the initial fit clearance. During the normal and stable operation of the metallic stator PCP, the slippage between cavities is consistent along the pump body. Therefore, one specific cavity in a steady state is focused on to model the clearance geometry between cavities. The geometric dimensions of the sealing regions in Figure 3 can be calculated in detail on the basis of the meshing profiles in Figure 4 and the spiral structures of the rotor and stator.

3.3.1. Transversal Slippage Clearance Geometry. As the transversal slippage occurs at the meshing points at straight sections of the stator (lines AF and CD as shown in Figure 4(a)), the cross-section of this sealing region satisfies the structure condition of a cylinder and a plane with a small clearance between them. As shown in Figure 14, the height of the transversal sealing region is variable along the clearance gap, which is minimal exactly at the meshing point in the center and becomes larger on both sides. Referring to Appendix, the height and length of the transversal sealing region can be calculated as follows:

$$
\begin{aligned}
h_{\mathrm{T}}(x) & =\delta+\frac{x^{2}}{d_{\mathrm{r}}}, \quad x \in\left[-0.475 \sqrt{d_{\mathrm{r}} \delta}, 0.475 \sqrt{d_{\mathrm{r}} \delta}\right] \\
L_{\mathrm{T}} & =0.95 \sqrt{d_{\mathrm{r}} \delta}
\end{aligned}
$$

where $h_{\mathrm{T}}(x)$ is the height of the transversal sealing region at different meshing points along the sealing line, $\mathrm{m} ; \delta$ is the fit clearance, $\mathrm{m} ; L_{\mathrm{T}}$ is the length of the transversal sealing region, m.

As the transversal sealing line is an envelope curve constituted by numerous meshing points, the width of the transversal sealing region can be calculated referring to the spiral curve equation of the rotor surface [29, 32], expressed as follows:

$$
\begin{aligned}
x & =\frac{d_{\mathrm{r}}}{2} \cos \beta+e \cos \alpha \\
y & =\frac{d_{\mathrm{r}}}{2} \sin \beta+e \sin \alpha \\
z & =\frac{\alpha}{2 \pi} \cdot \frac{T}{2} \\
0 & \leq \beta \leq 2 \pi \\
b_{\mathrm{T}} & =\int_{0}^{2 \pi} \sqrt{\left(\frac{\mathrm{d} x}{\mathrm{~d} \alpha}\right)^{2}+\left(\frac{\mathrm{d} y}{\mathrm{~d} \alpha}\right)^{2}+\left(\frac{\mathrm{d} z}{\mathrm{~d} \alpha}\right)^{2}} \mathrm{~d} \alpha \\
& =\sqrt{4 \pi^{2} e^{2}+\frac{T^{2}}{4}}
\end{aligned}
$$




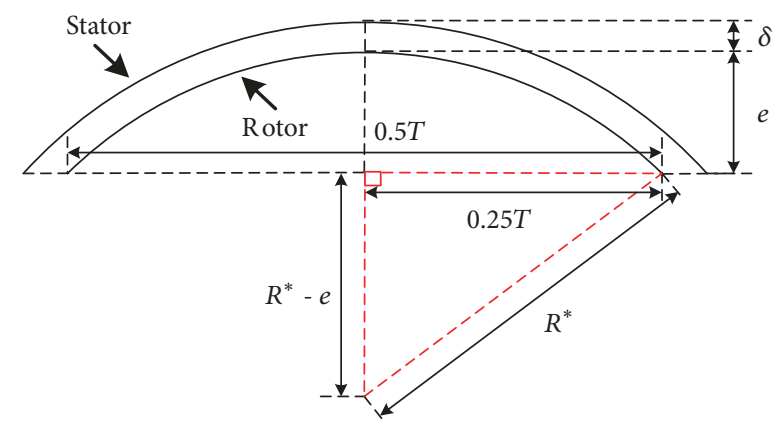

FIGURE 5: Axial cross-section of line meshing position between the stator and rotor.

where $b_{\mathrm{T}}$ is the width of the transversal sealing region, $\mathrm{m} ; \alpha$ and $\beta$ are the rotation angles of the rotor, respectively, relative to the center of the stator and the axis of the rotor.

3.3.2. Longitudinal Slippage Clearance Geometry. For the longitudinal slippage, it occurs at the meshing lines at fixed positions of the rotor (arcs $\mathrm{ABC}$ or DEF as shown in Figure 4(b)). The corresponding cross-section satisfies the structure condition between two inscribed cylinders. However, due to the complex spiral structures of the rotor and stator, the axial cross-section of the longitudinal sealing region is slightly irregular. In order to calculate its length by applying the lubrication theory, the geometry of the sealing region should be considered equivalently. Combining Figure 3(b), the axial cross-section of the meshing position along the flow transmission direction is equivalently shown in Figure 5.

In Figure 5, the inner cylinder depends on the spiral curve equation of the rotor, while outer cylinder is related to the profile equation of the stator. According to the geometric relationship of the PCP structure parameters including the clearance, the pitch, and the eccentricity, it can be calculated as

$$
R^{*}=\frac{e}{2}+\frac{T^{2}}{32 e}
$$

where $R^{*}$ is the equivalent radius of the inner cylinder in the axial cross-section, $\mathrm{m}$.

As the geometric dimensions of the longitudinal sealing region are relatively smaller compared with the basic pump size, the distance between the metallic stator and rotor in the axial cross-section in Figure 5 can also be viewed as the fit clearance $\delta$. Therefore, the radius of the outer cylinder equals $R^{*}+\delta$. Referring to Appendix, the length of the longitudinal sealing region can be obtained from the equivalent geometrical parameters of two inscribed cylinders, given as

$$
\begin{aligned}
R & =\frac{R^{*}\left(R^{*}+\delta\right)}{\delta} \\
& =\frac{\left(e / 2+T^{2} / 32 e\right)\left(e / 2+T^{2} / 32 e+\delta\right)}{\delta}
\end{aligned}
$$

$$
\begin{aligned}
L_{\mathrm{L}} & =0.95 \sqrt{2 R \delta} \\
& =0.95 \sqrt{2\left(\frac{e}{2}+\frac{T^{2}}{32 e}\right)\left(\frac{e}{2}+\frac{T^{2}}{32 e}+\delta\right)}
\end{aligned}
$$

where $R$ is the equivalent radius of curvature for the longitudinal clearance structure; $L_{\mathrm{L}}$ is the equivalent length of the longitudinal sealing region.

In accordance with the meshing positions of the longitudinal sealing in Figure 4(b) and the assumption of the uniform clearance fit between the rotor and stator, the height of the longitudinal sealing region can be expressed as the fit clearance, namely, $h_{\mathrm{L}}=\delta$. In addition, the width of the longitudinal sealing region can be represented as half of the rotor perimeter, given as

$$
b_{\mathrm{L}}=\frac{\pi d_{\mathrm{r}}}{2}
$$

where $b_{\mathrm{L}}$ is the width of the longitudinal sealing region, $\mathrm{m}$.

The geometric dimensions of sealing regions in this section are calculated for the single-lobe PCP. It is notable that the calculation methods can be extended to the multilobe PCP as long as the sealing regions are well learned on the basis of relevant pump structures. Nonetheless, the computational complexity will increase significantly with the increase of the stator lobe number, which can lead to greater challenges in solutions. In accordance with the common types of metallic stator PCPs in current field applications, the model in this study is mainly developed for the single-lobe PCP.

\subsection{Model Development}

3.4.1. Transversal Slippage. In consideration of the variable height along the transversal sealing lines, the height and length can be synthesized with the integrating process based on (6). Then the total slippage at two transversal sealing lines (formed by meshing points along line $\mathrm{AF}$ and $\mathrm{CD}$ in Figure 4(a)) due to the differential pressure can be calculated as

$$
q_{\mathrm{Tp}}=2 \times \frac{b_{\mathrm{T}}}{12 \mu} \frac{0.5 \Delta P}{\int_{-L_{\mathrm{T}} / 2}^{L_{\mathrm{T}} / 2} h_{\mathrm{T}}^{-3}(x) d x}
$$

where $q_{\mathrm{Tp}}$ is the transversal slippage due to the differential pressure, $\mathrm{m}^{3} / \mathrm{s}$.

Combined with (14) and (15) by numerical transformation, (22) can be simplified as

$$
\begin{aligned}
q_{\mathrm{Tp}} & =\beta \frac{b_{\mathrm{T}} \delta^{3} \Delta P}{12 \mu L_{\mathrm{T}}} \\
\beta & =\frac{1}{\int_{0}^{1}\left[1+(0.475 x)^{2}\right]^{-3} d x} \approx 1.2158
\end{aligned}
$$

where $\beta$ is a computing coefficient derived from numerical transformation, dimensionless.

For the meshing points on the transversal sealing lines (shown in Figures 3(a) and 4(a)), it is speedless in the X 
direction. As the rotor rotation movement corresponding to the velocity $v_{\mathrm{y} 1}(t)$ in the $\mathrm{Y}$ direction causes slippage from cavity $i+1$ to $i$ and from cavity $i$ to $i+1$ simultaneously, these two slippage components counteract each other. Therefore, the actual relative velocity influencing the transversal slippage mainly consists of the velocity of reciprocating motion in the $\mathrm{Y}$ direction $v_{\mathrm{y} 2}(t)$ and the velocity in the $\mathrm{Z}$ direction $v_{\mathrm{z}}$; thus the resultant velocity can be calculated as

$$
v_{\mathrm{T}}(t)=\sqrt{v_{\mathrm{y} 2}^{2}(t)+v_{\mathrm{z}}^{2}}
$$

Considering that the resultant velocity $v_{\mathrm{T}}(t)$ is timedependent at each meshing point and two transversal sealing lines between adjacent cavities are corresponding to half of the stator pitch with rotation time duration $t_{0.5}=1 / 2 n$, the transversal slippage due to the relative motion can be calculated as

$$
q_{\mathrm{Tv}}=2 \times \frac{\int_{0}^{1 / 2 n}\left(b_{\mathrm{T}} \delta / 2\right) v_{\mathrm{T}}(t) \mathrm{d} t}{1 / 2 n}
$$

where $q_{\mathrm{T} v}$ is the transversal slippage due to the relative motion between the stator and rotor, $\mathrm{m}^{3} / \mathrm{s}$.

Combining (11), (13), and (25), (26) can be simplified by numerical transformation, given as

$$
\begin{aligned}
& q_{\mathrm{Tv}}=\frac{b_{\mathrm{T}} \delta}{2} \overline{\nu_{\mathrm{T}}} \\
& \overline{\nu_{\mathrm{T}}}=\frac{n}{30} \times \int_{0}^{1} \sqrt{\left(4 \pi e \sin \frac{\pi x}{60}\right)^{2}+T^{2}} d x
\end{aligned}
$$

where $\overline{v_{\mathrm{T}}}$ is the equivalent relative velocity which influences the transversal slippage, $\mathrm{m} / \mathrm{s}$.

As a result, the total transversal slippage can be obtained by combining (23) and (27):

$$
q_{\mathrm{T}}=\beta \frac{b_{\mathrm{T}} \delta^{3} \Delta P}{12 \mu L_{\mathrm{T}}}+\frac{b_{\mathrm{T}} \delta}{2} \overline{v_{\mathrm{T}}}
$$

where $q_{\mathrm{T}}$ is the total transversal slippage, $\mathrm{m}^{3} / \mathrm{s}$.

3.4.2. Longitudinal Slippage. As the resultant velocity $v_{\mathrm{xy}}$ of meshing points on the longitudinal sealing line (shown in Figure $4(\mathrm{~b}))$ is perpendicular to the direction of the slippage flow inside the PCP, the effect of $v_{x y}$ on the slippage can be neglected. Therefore, the relative velocity influencing the longitudinal slippage mainly comes from the axial velocity along the fluid transmission direction, given as

$$
\overline{v_{\mathrm{L}}}=v_{z}
$$

where $\overline{v_{\mathrm{L}}}$ is the equivalent relative velocity which influences the longitudinal slippage, $\mathrm{m} / \mathrm{s}$.

Based on the analyses of the velocity and longitudinal slippage clearance geometry, the total longitudinal slippage can be obtained directly by combining (5), (6) and (7), given as

$$
q_{\mathrm{L}}=\frac{b_{\mathrm{L}} \delta^{3} \Delta P}{12 \mu L_{\mathrm{L}}}+\frac{b_{\mathrm{L}} \delta}{2} \overline{v_{\mathrm{L}}}
$$

where $q_{\mathrm{L}}$ is the total longitudinal slippage, $\mathrm{m}^{3} / \mathrm{s}$.
3.4.3. Flow Rate of the Metallic Stator PCP in Clearance Fit. As is known that the total slippage is the sum of the slippage in two directions, it can be derived by combining (29) and (31). Based on the relationship between the total lifting pressure $\Delta P_{\mathrm{p}}$ and the single-stage pressure difference $\Delta P$, a simplified formula for the total slippage considering different slippage mechanisms is given as

$$
\begin{aligned}
& q=\xi \frac{\delta^{3} \Delta P_{\mathrm{P}}}{12 \mu N}+\varphi \frac{\delta n}{2} \\
& \xi=\beta \frac{b_{\mathrm{T}}}{L_{\mathrm{T}}}+\frac{b_{\mathrm{L}}}{L_{\mathrm{L}}} \\
& \varphi=\frac{1}{n}\left(b_{\mathrm{T}} \overline{v_{\mathrm{T}}}+b_{\mathrm{L}} \overline{v_{\mathrm{L}}}\right)
\end{aligned}
$$

where $\xi$ and $\varphi$ are the slippage channel parameters respectively due to the differential pressure and the relative motion between the stator and rotor. It is notable that both $\xi$ and $\varphi$ depend on basic geometrical parameters of the pump.

According to the performance characteristics of positive displacement pumps, the actual flow rate in the metallic stator PCP can be obtained by subtracting the total slippage from the theoretical volumetric rate, given as

$$
Q=Q_{t}-86400 q
$$

where $Q$ is the actual flow rate, $\mathrm{m}^{3} / \mathrm{d}$.

Then the volumetric efficiency of the metallic stator PCP, namely, the ratio of the actual flow rate to the theoretical volumetric rate, is given as

$$
\eta_{\mathrm{v}}=\frac{\mathrm{Q}}{\mathrm{Q}_{\mathrm{t}}} \times 100 \%
$$

where $\eta_{\mathrm{v}}$ is the pump volumetric efficiency.

\section{Performance Experiments}

In order to validate the model proposed for the flow in the metallic stator PCP, laboratory experiments were conducted by using a special experimental platform for PCP performance, as shown in Figure 6. It mainly consists of the data transmission/acquisition system and the fluid circulation system. In the data transmission/acquisition system, the rotor of PCP is driven by the electric motor. The frequency converter is applied to adjust the rotor speed, and the torque/speed sensor is used to measure the rotational speed and the torque. These measured data can be acquired and recorded by the computer. In the fluid circulation system, the oil in the tank is pumped by the PCP from the inlet to the outlet, and then flow back into the tank. Two pressure transmitters are installed at both sides of the PCP to measure the intake and discharge pressures. The loading valve is used to adjust the discharge pressure at the outlet, and the flowmeter is used to measure the flow rate through the PCP.

The experiments were conducted under certain operational conditions, considering both the situations in field pump applications and the operational ability of the experimental platform. The pressure difference between the outlet 


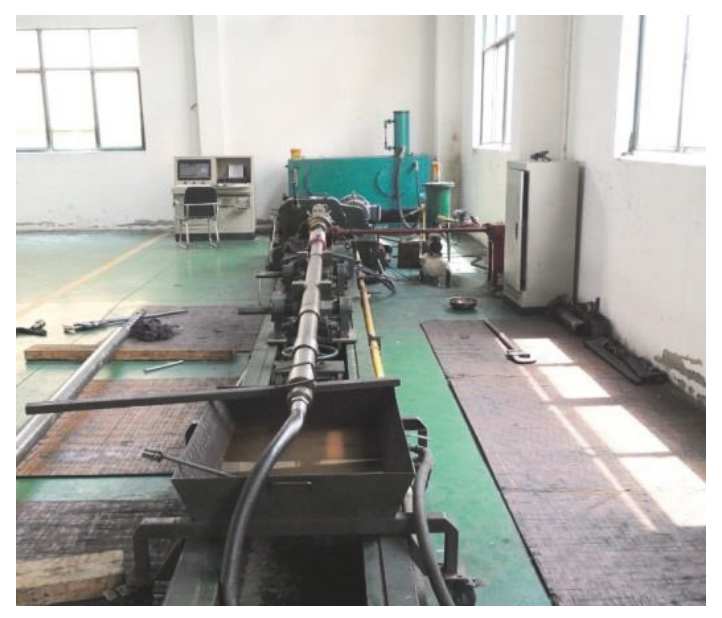

(a) Actual apparatus of PCP performance experiments

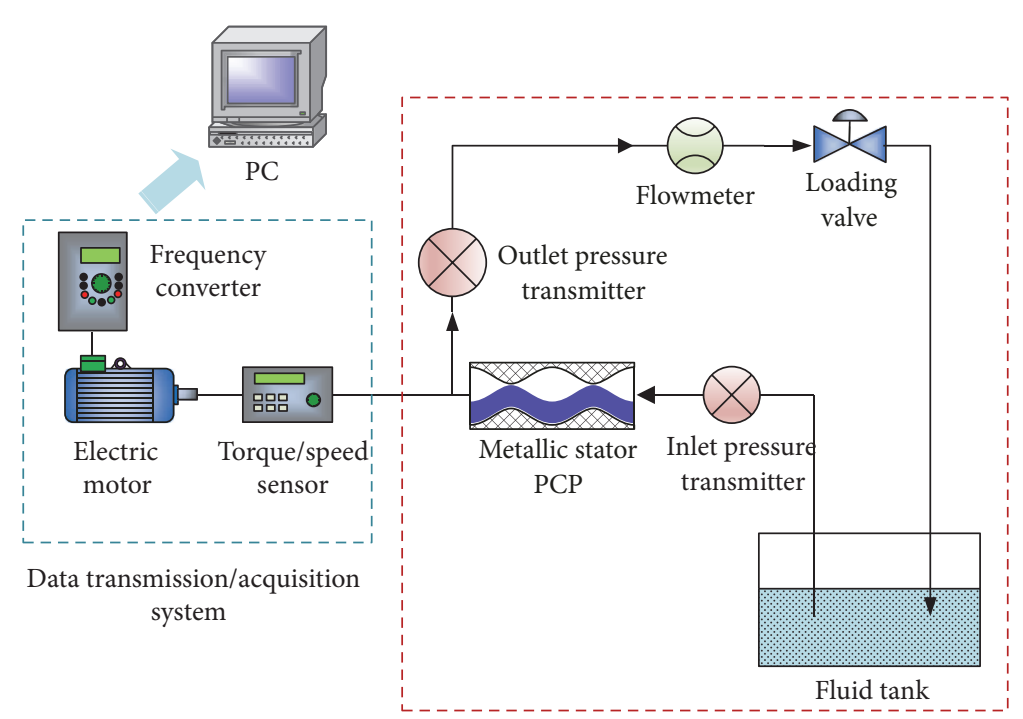

Fluid circulation system

(b) Flow diagram of PCP performance experiments

FIGURE 6: Schematic of experimental platform for PCP performance.

and the inlet was maintained at the range of $0 \mathrm{MPa}$ to $14 \mathrm{MPa}$ by adjusting the loading valve. The tested fluids were the 32 \# and 68 \# hydraulic oil, respectively, with the viscosity of 65 $\mathrm{mPa} \cdot \mathrm{s}$ and $157 \mathrm{mPa} \cdot \mathrm{s}$ at the temperature of $26^{\circ} \mathrm{C}$.

The pumps tested in this study were two types of commercial metallic stator PCP products from Shihong Petroleum Equipment Company, whose geometrical parameters are shown in Table 1. With reference to the modeling process of the clearance geometry between cavities, the correction factor $\alpha$, and the slippage channel parameters $\xi, \varphi$ can be calculated, which are also given in the table.

\section{Results and Discussion}

5.1. Model Validation. According to the proposed model, the actual flow rate can be predicted under different conditions. For the cases of the pumps operating at $100 \mathrm{r} / \mathrm{min}, 150$ $\mathrm{r} / \mathrm{min}$ and $200 \mathrm{r} / \mathrm{min}$, the results obtained by the model are compared with the experimental results at different pressures. Figures 7 and 8, respectively, show the comparison results of JDGLB160-12 and JDGLB350-8 for pumping different hydraulic oil. As illustrated in the figures for different cases, the flow rate decreases linearly with the increase of the differential pressure. And the corresponding relation curves obtained from one specific group of experiments are almost parallel at different rotational speeds, presenting the same decline tendency. It is notable that this decline tendency for pumping 68 \# hydraulic oil is weaker than that for pumping 32 \# hydraulic oil.

As shown in Figures 7 and 8, very good agreement is observed between the model results and the experimental results. The corresponding relative errors for four groups of comparison results are shown in Figure 9. The overall errors are demonstrated to be below $4 \%$. As a result, the accuracy of the proposed model for the flow in the metallic stator PCP is well validated.
With an analytical model proposed and validated above, a simulator for the flow in the metallic stator PCP can be developed on the basis of the modeling process. It can be applied as a feasible tool for field engineers to predict the pump performance under certain conditions and provide relevant guidance for effective applications.

5.2. Pump Types and Pump Design. For specific pump series provided by manufacturers, there are usually different types of pumps with various fit clearance and pump stages, providing choices for pump applications. The fit clearance between the stator and rotor and the number of pump stages are two important geometrical parameters having significant effects on the pump performance. For the pump series of JDGLB160 with certain basic parameters $\left(e=5 \mathrm{~mm}, d_{\mathrm{r}}=50 \mathrm{~mm}\right.$, and $T=160 \mathrm{~mm}$ ), the relevant details are analyzed in the following.

\subsubsection{Effects of Geometrical Parameters on Pump Performance.} Figure 10 illustrates the effect of the fit clearance between the stator and rotor on the pump performance. The results are obtained for the pump with 12 stages at $n=100 \mathrm{r} / \mathrm{min}$ and $\mu=100 \mathrm{mPa} \cdot \mathrm{s}$. As the clearance increases, the flow rate decreases at certain differential pressures. Large clearance favors the slippage flow and in turn reduces the flow rate, which is more significant at higher differential pressure. But when there is no pressure difference $\left(\Delta P_{\mathrm{p}}=0 \mathrm{MPa}\right)$, the flow rate increases slightly as the clearance rises. In this situation, there is no slippage caused by differential pressure, and the increment of theoretical volumetric rate due to the clearance increase is slightly larger than the slippage simply caused by the rotor rotation.

With the specific clearance between the stator and rotor $(\delta=0.1 \mathrm{~mm})$, the pumps with different stages can be simulated to analyze the effect of the number of pump stages on the pump performance, as shown in Figure 11. The results are obtained at various differential pressures in the case of $n=50$ 
TABLE 1: Geometrical parameters of tested metallic stator PCPs.

\begin{tabular}{lccccccccc}
\hline \multirow{2}{*}{ Pump type } & \multicolumn{4}{c}{ Basic geometrical parameters } & \multicolumn{4}{c}{ Calculated parameters } \\
& $q_{\mathrm{r}}, \mathrm{ml} / \mathrm{r}$ & $N$ & $T, \mathrm{~mm}$ & $e, \mathrm{~mm}$ & $d_{\mathrm{r}}, \mathrm{mm}$ & $\delta, \mathrm{mm}$ & $\alpha, 10^{-2}$ & $\xi$ & $\varphi, 10^{-3} \mathrm{~m}^{2}$ \\
\hline JDGLB160-12 & 160 & 12 & 160 & 5 & 50 & 0.1 & 1.97 & 49.55 \\
JDGLB350-8 & 351.232 & 8 & 224 & 7 & 56 & 0.15 & 2.22 & 53.42 \\
\hline
\end{tabular}

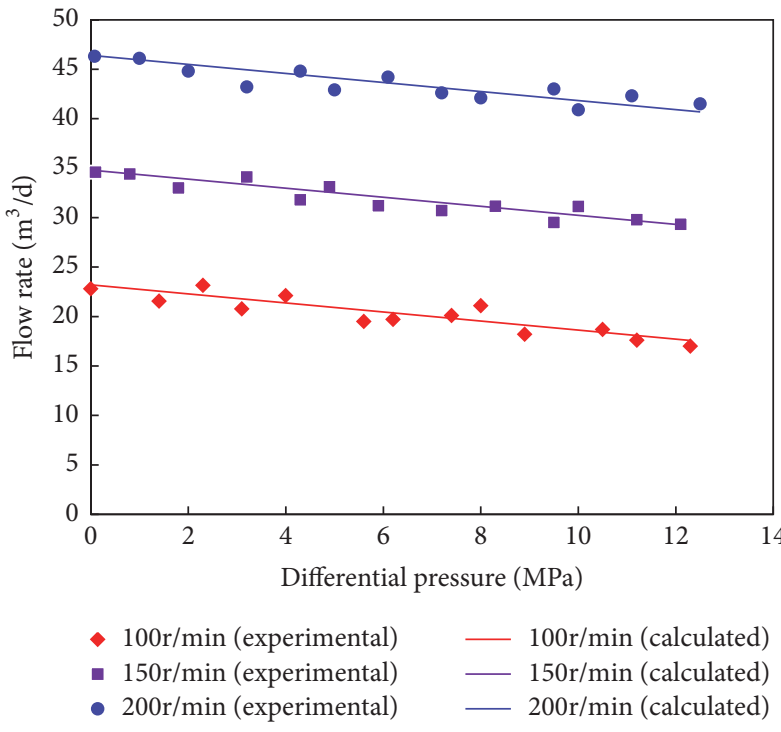

(a) 32\# hydraulic oil

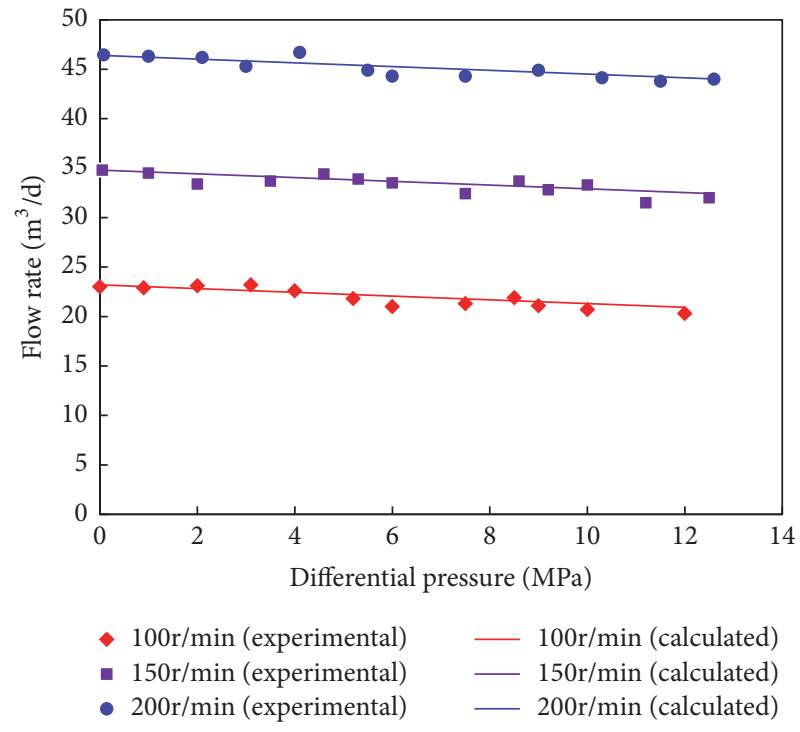

(b) 68\# hydraulic oil

FIGURE 7: Comparison between model results and experimental results of JDGLB160-12.

$\mathrm{r} / \mathrm{min}$ and $\mu=50 \mathrm{mPa} \cdot \mathrm{s}$. When the differential pressure is zero, the number of pump stages has no influence on the flow rate, in which no slippage occurs due to the differential pressure. At certain differential pressure, the flow rate can be raised by increasing the number of pump stages. As is known in (3), the theoretical volumetric rate is independent of the number of pump stages. But for the pump with more stages, the pressure difference between two consecutive cavities decreases, which can significantly reduce the negative influence of slippage due to the differential pressure on the pump performance.

5.2.2. Guidance for Pump Design in Application. It needs to be noted that, under specific operating conditions, there is a maximum clearance or a minimum number of pump stages that maintains the pump flow rate. In order to achieve the fluid pumping at $\Delta P_{\mathrm{p}}=12 \mathrm{MPa}$, the clearance has to be below $0.22 \mathrm{~mm}$ for the case in Figure 10, while the number of pump stages has to be above 8 for the case in Figure 11. Therefore, the geometrical parameters including the clearance and the number of pump stages should be well designed for the pump used in the well production, which demonstrates the importance of selecting pump types in field applications. Theoretically, the metallic stator PCP with smaller clearance or more stages is more likely to achieve good performance under certain operating conditions. However, for the mature pump products from manufacturers, the available metallic stator PCPs are usually confined to some specific types, in which there are less alternatives of the clearance than that of the pump stages. Moreover, if the clearance is designed to be too small, the friction between the stator and rotor will increase seriously. As a result, it is more feasible and preferable to design the number of pump stages in the pump applications based on the available clearance. For the artificial lift system of a deep well, the pump with more stages can be adopted to satisfy the demand of the relative high pumping head.

5.3. Operating Conditions and Performance Optimization. In addition to the geometrical parameters related to the basic pump structure, the pump performance is also affected by the operating conditions, including the fluid viscosity, rotational speed, and differential pressure. According to the proposed model, the pump performance curves can be constructed to present the relationship between the pump volumetric efficiency and the differential pressure under different conditions. It can provide some guidance for the performance optimization of the metallic stator PCP in applications.

5.3.1. Pump Performance under Different Operating Conditions. Figure 12 shows the pump performance curves at different liquid viscosities, which are simulated for the pump with 12 stages at $n=100 \mathrm{r} / \mathrm{min}$. With the increase of the differential pressure, the volumetric efficiency decreases due to the stronger slippage caused by the differential pressure, but the decrement becomes much weaker at higher liquid viscosity. In the operation of pumping the liquid with high viscosity, there is large viscous resistance acting as a sealing 


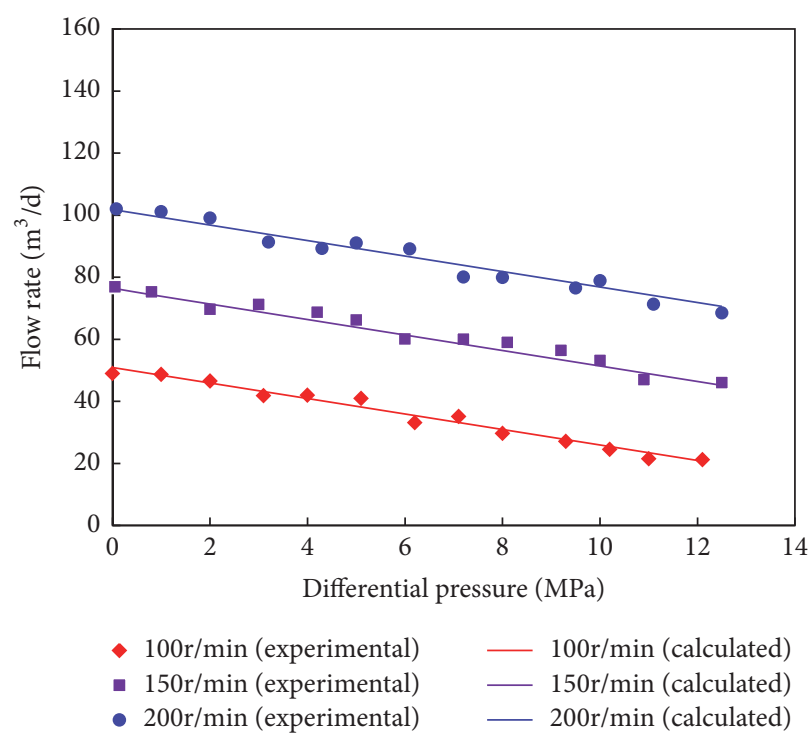

(a) 32\# hydraulic oil

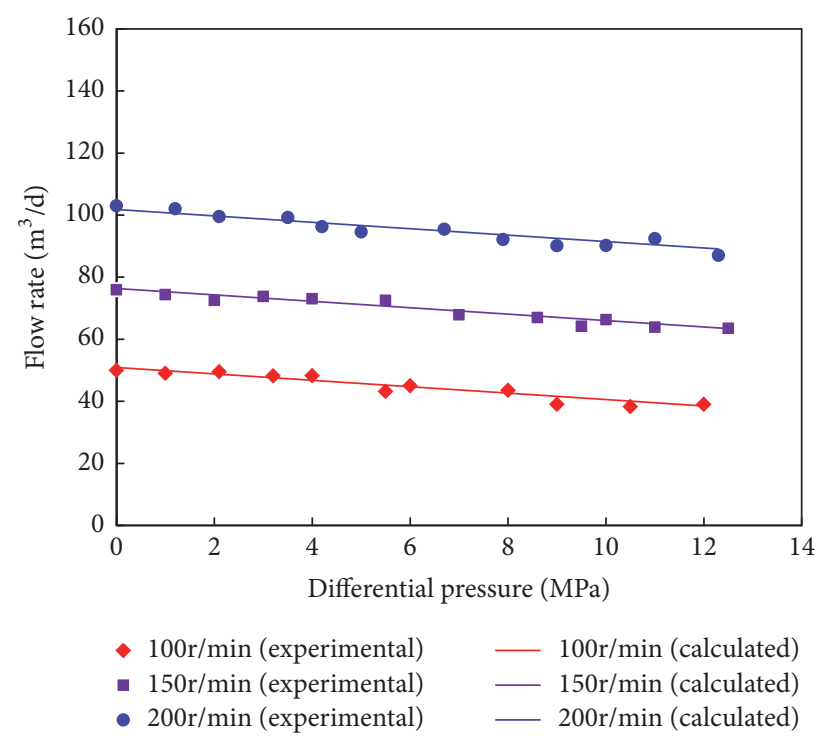

(b) 68\# hydraulic oil

FIGURE 8: Comparison between model results and experimental results of JDGLB350-8.

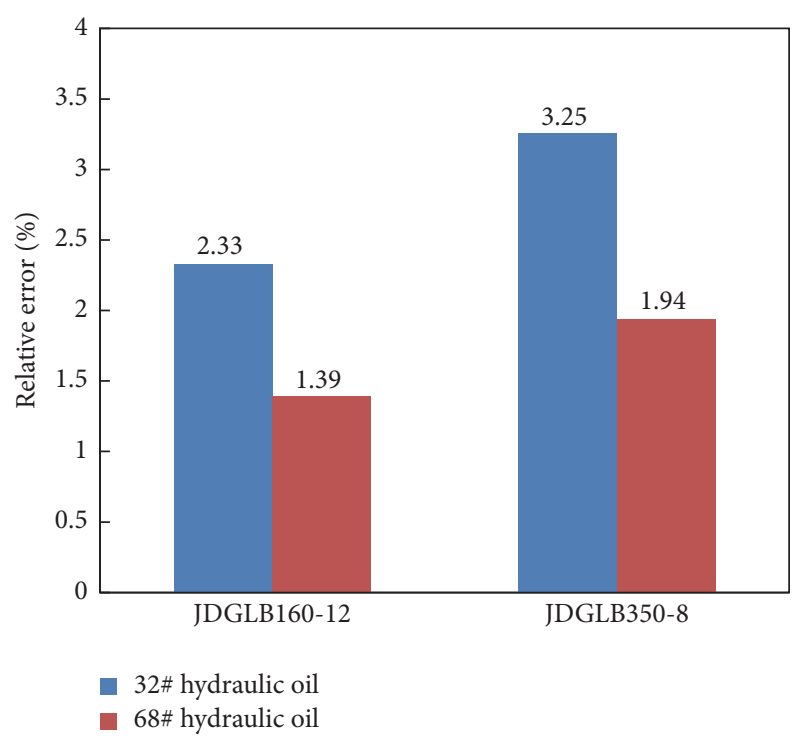

FIGURE 9: Relative error analysis of four groups of comparison results.

effect in the clearance between cavities, which can reduce the slippage and achieve high flow rate. As shown in Figure 12 at $\Delta P_{\mathrm{p}}=12 \mathrm{MPa}$, when the liquid viscosity increases from 100 $\mathrm{mPa} \cdot \mathrm{s}$ to $200 \mathrm{mPa} \cdot \mathrm{s}$, the volumetric efficiency achieves a rise of $20.76 \%$.

The pump performance curves at different rotational speeds are constructed for the pump with 12 stages at $\mu=$ $50 \mathrm{mPa} \cdot \mathrm{s}$, as shown in Figure 13. At specific differential pressure, the volumetric efficiency can be significantly raised by increasing the rotational speed. When the rotational speed increases from $100 \mathrm{r} / \mathrm{min}$ to $400 \mathrm{r} / \mathrm{min}$ at $\Delta P_{\mathrm{p}}=12 \mathrm{MPa}$, the slippage due to the differential pressure is constant, while

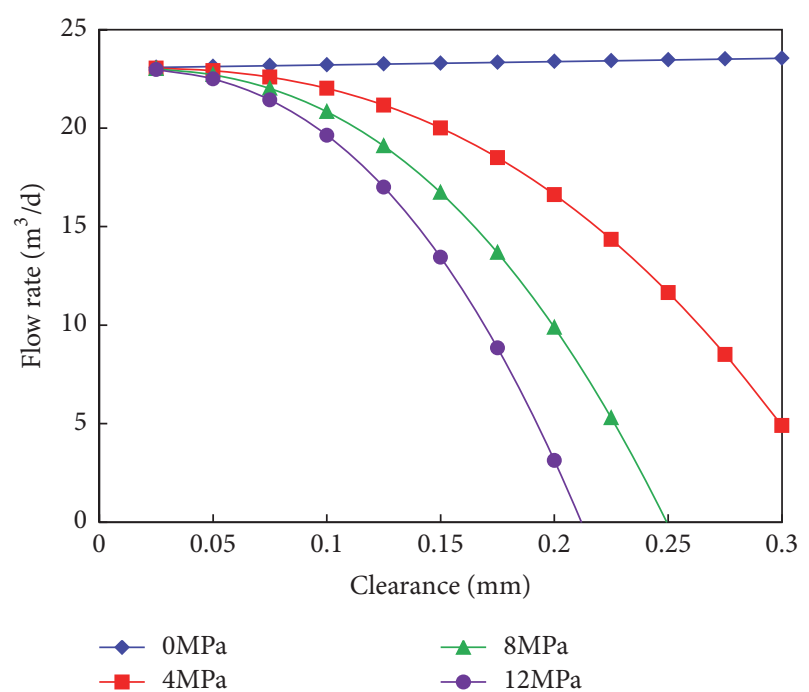

FIGURE 10: Effect of fit clearance between the stator and rotor on pump performance $(n=100 \mathrm{r} / \mathrm{min}, \mu=100 \mathrm{mPa} \cdot \mathrm{s}, N=12)$.

the slippage due to the rotor rotation increases only 1.3 $\mathrm{m}^{3} / \mathrm{d}$. However, the theoretical rate quadruples from 23.72 $\mathrm{m}^{3} / \mathrm{d}$ to $94.88 \mathrm{~m}^{3} / \mathrm{d}$, which increases much more rapidly than the total slippage. As a result, the pump volumetric efficiency achieves a significant rise of $62.27 \%$. In other words, relative high rotational speed can be properly adopted to compensate the influence of the slippage on the pump performance.

According to the slippage mechanisms, the effects of the differential pressure and rotational speed on the pump performance are corresponding to two slippage components, respectively, $q_{\mathrm{p}}$ and $q_{\mathrm{v}}$. Based on the definition of the pump volumetric efficiency, the volumetric efficiency loss can 


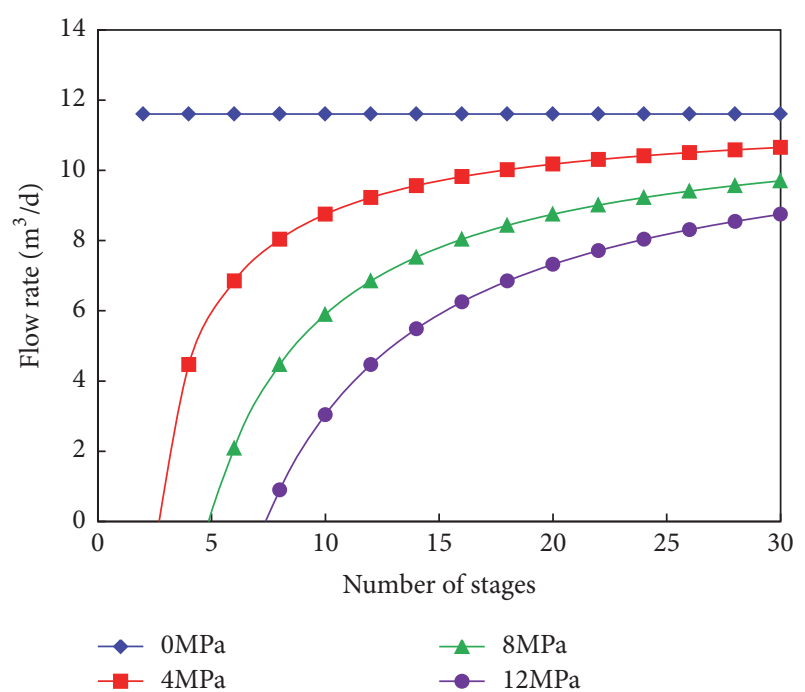

FIGURE 11: Effect of the number of pump stages on pump performance $(n=50 \mathrm{r} / \mathrm{min}, \mu=50 \mathrm{mPa} \cdot \mathrm{s}, \delta=0.1 \mathrm{~mm})$.

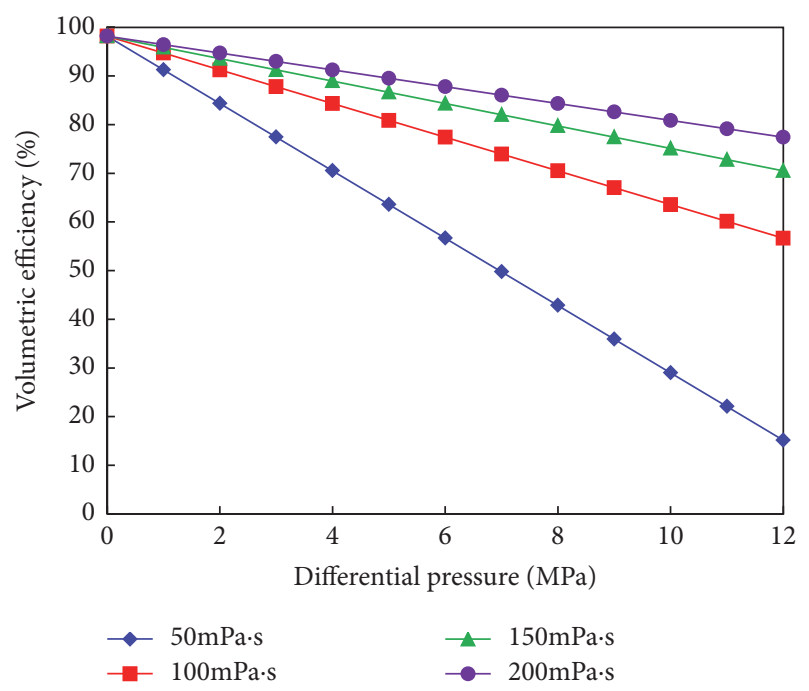

Figure 12: Pump performance curves at different liquid viscosities $(n=100 \mathrm{r} / \mathrm{min}, \delta=0.15 \mathrm{~mm}, N=12)$.

represent a measure of the dimensionless slippage, namely, the ratio of the total slippage to the theoretical volumetric rate. As shown in Figures 12 and 13, the linear decrease of the volumetric efficiency is corresponding to the dimensionless slippage due to the differential pressure $\left(q_{\mathrm{p}} / Q_{\mathrm{t}}\right)$. In addition, it needs to be noted that the volumetric efficiency at zero differential pressure maintains a constant slightly smaller than $100 \%$, between which the small difference is about $1.83 \%$. This part of volumetric efficiency loss is determined by the dimensionless slippage due to the rotor motion $\left(q_{\mathrm{v}} / Q_{\mathrm{t}}\right)$. As the pump is generally placed in a well with certain lifting pressure, the volumetric efficiency loss caused by the differential pressure is many times larger than that caused by the rotor motion. In other words, the slippage due to the differential pressure plays the dominant role in influencing the pump performance.

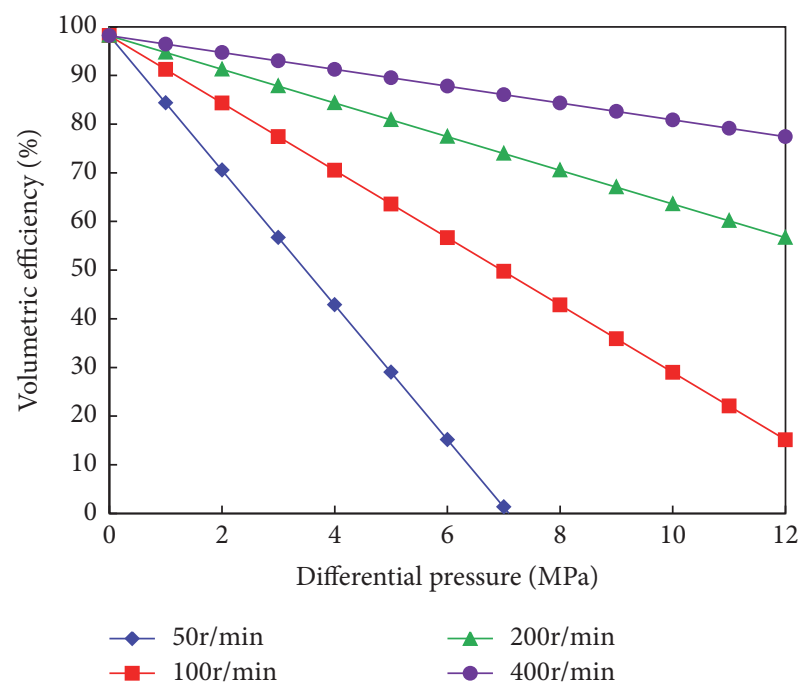

Figure 13: Pump performance curves at different rotational speeds $(\mu=50 \mathrm{mPa} \cdot \mathrm{s}, \delta=0.15 \mathrm{~mm}, N=12)$.

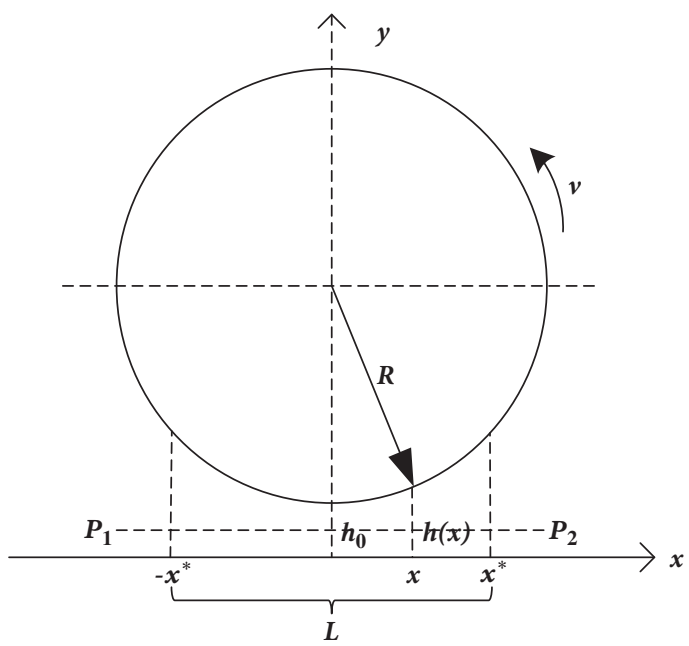

FIGURE 14: The cross-section of the equivalent cylinder and plane.

5.3.2. Guidance for Performance Optimization in Application. Considering the influence of the liquid viscosity on the pump performance, it can be known that the metallic stator PCP has a good adaptability for pumping the viscous oil. However, it cannot be directly concluded that the higher the oil viscosity is, the better the pump performs. It is a remarkable fact that when the oil viscosity is too high, it can be difficult for the pump cavities to be full filled with oil under certain inlet pressure, which can in turn limit the pump volumetric efficiency. This is also why the thermal recovery methods that aim at viscosity reduction have been widely applied to the heavy oil production. In the actual thermal recovery process, due to the variability of the oil viscosity with the thermal recovery temperature, the rotational speed should be adjusted in real time. In the earlier stage, for the oil at higher temperature which has lower viscosity, higher rotational speed can be adopted to ensure the pump performance. In the later stage, since the oil cools down gradually and its viscosity 
becomes higher, the rotational speed can be appropriately reduced to give full play to the pumping capacity for viscous fluid.

When it comes to the cold production that the oil easily fills the pump cavities, it is feasible to modestly increase the rotational speed for the pump performance assurance. Particularly in the cases where the oil well produces water to a certain extent, higher rotational speed should be adopted to compensate the relatively serious influence of the slippage in the artificial lift of the lower viscosity fluid.

\section{Conclusions}

This paper provides an analytical model for the flow in the metallic stator PCP operating with the stator and rotor in clearance fit. The model is established on the basis of slippage through the clearance between cavities, which contributes to a better understanding of the pump performance. The following conclusions are drawn.

(1) The proposed model overcomes several weaknesses of the existing analytical methods to model the flow more rigorously and comprehensively. Slippage flow occurs through the sealing lines between cavities simultaneously in the transversal and longitudinal directions. The accurate calculation of total slippage should consider two slippage components respectively due to the differential pressure and the relative motion between the rotor and stator, and solve the geometrical parameters of relevant slippage channels. It shows that the slippage due to the differential pressure plays the dominant role in influencing the pump performance.

(2) The model results are consistent with the experimental data of commercial metallic stator PCP products, which verifies the accuracy of the proposed model. The model can be applied as a feasible tool for field engineers to predict the pump performance under certain conditions. Based on the effects of geometrical and operating parameters on the pump performance, the model can provide relevant guidance for effective applications, including pump design and performance optimization under well production conditions.

(3) It is important to select the appropriate pump type in consideration of the geometrical parameters in field applications. The metallic stator PCP with smaller clearance or more stages is more likely to achieve good performance at high differential pressure. Based on the available clearance of existing metallic stator PCP products, it is more feasible and preferable to design the number of pump stages.

(4) The metallic stator PCP in clearance fit has a good adaptability for pumping the viscous fluid. Though the pump operates with the slippage, its negative influence on the pump performance can be greatly compensated by appropriately raising the rotational speed. When the pump is applied to well productions in the field, the rotational speed should be adjusted in real time according to the variation of the fluid property in the production process.

\section{Appendix}

Based on the lubrication theory about two rigid bodies with a small clearance between them $[30,31]$, the line contact of two cylinders with arbitrary cross-section can be transformed into the uniform contact issue of an equivalent cylinder and a plane by geometric simulation, as shown in Figure 14. The geometric dimensions of the sealing region between these two bodies can be described by the liquid film in the small clearance.

For three different cross-section structures, the uniform derivation is given as

$$
\begin{gathered}
R= \begin{cases}R_{0}, & \text { a cylinder and a plane } \\
\frac{R_{1} R_{2}}{R_{1}+R_{2}}, & \text { two circumscribed cylinders } \\
\frac{R_{1} R_{2}}{R_{1}-R_{2}}, & \text { two inscribed cylinders }\end{cases} \\
h(x)=h_{0}+\left(R-\sqrt{R^{2}-x^{2}}\right) \approx h_{0}+\frac{x^{2}}{2 R}
\end{gathered}
$$

where $R$ is the radius of curvature of the equivalent cylinder, $\mathrm{m} ; R_{0}$ is the radius of the single cylinder in the contact section, $\mathrm{m} ; R_{1}, R_{2}$ are, respectively, the radius of two cylinders in the contact section, $\mathrm{m} ; h(x)$ is the thickness of the liquid film, $\mathrm{m} ; h_{0}$ is the liquid film thickness at the center line, which represents the minimum clearance, $\mathrm{m}$.

Then the length of the liquid film along the clearance can be obtained as

$$
\begin{gathered}
x^{*}=\tan 25^{\circ} 25^{\prime} \sqrt{2 R h_{0}} \\
L=2 x^{*} \approx 0.95 \sqrt{2 R h_{0}}
\end{gathered}
$$

where $x^{*}$ is the distance between the liquid film breakdown point and the center line, corresponding to the position where the pressure gradient becomes zero, $\mathrm{m}$; $L$ is the equivalent length of the liquid film, $\mathrm{m}$.

\section{Nomenclature}

A: Cross-sectional area, $\mathrm{m}^{2}$

b: Width, $\mathrm{m}$

$d$ : Diameter, $\mathrm{m}$

e: $\quad$ Rotor eccentricity, $\mathrm{m}$

h: Height, $\mathrm{m}$

i: Number of cavities

L: $\quad$ Length, $\mathrm{m}$

$N$ : Number of pump stages

$n$ : $\quad$ Rotational speed, $\mathrm{r} / \mathrm{min}$

$\Delta P_{s}:$ Differential pressure causing slippage, $\mathrm{Pa}$

$\Delta P:$ Single-stage pressure difference, $\mathrm{Pa}$

$\Delta P_{\mathrm{p}}$ : Total lifting pressure of pump, $\mathrm{Pa}$

$Q_{\mathrm{t}}: \quad$ Theoretical volumetric rate, $\mathrm{m}^{3} / \mathrm{d}$

Q: Actual flow rate, $\mathrm{m}^{3} / \mathrm{d}$

q: $\quad$ Slippage, $\mathrm{m}^{3} / \mathrm{s}$

$q_{\mathrm{r}}$ : Single-rotation theoretical rate, $\mathrm{m}^{3} / \mathrm{r}$

$q^{*}:$ Dimensionless slippage

T: $\quad$ Stator pitch, $\mathrm{m}$

$t$ : Time, $s$

$v: \quad$ Velocity, $\mathrm{m} / \mathrm{s}$

$\bar{v}$ : Equivalent relative velocity, $\mathrm{m} / \mathrm{s}$. 


\section{Subscripts}

r: $\quad$ Rotor

s: $\quad$ Stator

T: Transversal direction

L: Longitudinal direction

p: $\quad$ Due to the differential pressure

v: Due to the relative motion

$\mathrm{x}, \mathrm{y}, \mathrm{z}$ : Coordinate orientation.

\section{Greek Letters}

$\alpha$ : Correction factor

$\beta$ : Computing coefficient

$\delta$ : Fit clearance, $\mathrm{m}$

$\mu$ : Fluid viscosity, $\mathrm{Pa} \cdot \mathrm{s}$

$\xi$ : Slippage channel parameters due to the differential pressure

$\varphi$ : Slippage channel parameters due to the relative motion, $\mathrm{m}^{2}$.

\section{Data Availability}

The data used to support the findings of this study are available from the corresponding author upon request.

\section{Conflicts of Interest}

The authors declare that there are no conflicts of interest regarding the publication of this paper.

\section{Acknowledgments}

This work was supported by the National Science and Technology Major Project Program (2017ZX05009-003) and the National Program on Key Basic Research Project (2015CB250906). The authors are also very grateful to Jiangsu Yancheng Shihong Petroleum Equipment Company for the valuable efforts.

\section{References}

[1] R. Moineau, A new capsulism [PhD. Thesis], University of Paris, Paris, France, 1930.

[2] M. Lehman, "Progressing cavity pumps in oil and gas production," World Pumps, no. 457, pp. 20-22, 2004.

[3] M. Lehman, "Large progressing cavity pumps for oil field transfer application," World Pumps, no. 467, pp. 28-30, 2005.

[4] L. Dunn, C. Matthews, and T. Zahacy, "Progressing Cavity Pumping System Applications in Heavy Oil Production," in Proceedings of the SPE International Heavy Oil Symposium, Calgary, Alberta, Canada.

[5] L. Ocanto and A. Rojas, "Progressing Cavity Pump Pattern Recognition in Heavy and Extra-Heavy Oil Cold Production," in Proceedings of the SPE International Thermal Operations and Heavy Oil Symposium, Paper SPE-69701, Porlamar, Margarita Island, Venezuela, March 2001.

[6] M. A. Ramos, J. C. Brown, M. Rojas, O. Kuyucu, and J. G. Flores, "Producing extra-heavy oil from the Orinoco belt, Cerro Negro area, Venezuela, using bottom-drive progressive cavity pumps," SPE Production and Operations, vol. 22, no. 2, pp. 151-155, 2007.

[7] H. Wang, S. Wang, and X. Lv, "The effects of temperature on the mechanical and tribological properties of progressing cavity pump NBR stator rubber," Mechanika, vol. 22, no. 4, pp. 308312, 2016.

[8] J.-L. Beauquin, C. Boireau, L. Lemay, and L. Seince, "Development status of a metal progressing cavity pump for heavy-oil and hot-production wells," Journal of Petroleum Technology, vol. 58, no. 5, pp. 59-61, 2006.

[9] S. G. Noonan, W. Klaczek, K. D. Piers, L. L. Seince, and S. Jahn, "Quest to Validate and Define Performance for the High Volume Metallic Stator PCP at 250C," in Proceedings of the International Thermal Operations and Heavy Oil Symposium, Paper SPE-117493, Calgary, Alberta, Canada, October 2008.

[10] K. Bybee, "First Metal-PCP SAGD Field Test Shows Promise for Heavy-Oil Hot Production," Journal of Petroleum Technology, vol. 60, no. 07, pp. 70-73, 2015.

[11] K. Bybee, "Experience With Metal PCPs in a Cuban Heavy-Oil Field," Journal of Petroleum Technology, vol. 61, no. 07, pp. 51-53, 2015.

[12] R. Arystanbay, W. Bae, H. X. Nguyen, S. Ryou, W. Lee, and T. Jang, "Succesful Application of Metal PCP Rechnology to Maximize Oil Recovery in SAGD Process," in Proceedings of the SPE Heavy Oil Conference and Exhibition, Kuwait City, Kuwait, December 2011.

[13] M. Arredondo, D. Caballero, R. Morety, A. Delgado, and B. Ortegano, "All metal PCP experiences in Orinoco Belt," in Proceedings of the SPE Artificial Lift Conference \&amp; ExhibitionNorth America, Paper SPE-171370, Houston, TX, USA, October 2014.

[14] M. Li, D. Jiang, H. Guo et al., "Study on clearance optimization of all-metal screw pumps: Experiment and simulation," Mechanika, vol. 23, no. 5, pp. 735-742, 2017.

[15] K. A. Woolsey, "Improving progressing-cavity-pump performance through automation and surveillance," Journal of Canadian Petroleum Technology, vol. 51, no. 1, pp. 74-81, 2012.

[16] E. E. Paladino, J. A. Lima, R. Almeida, and B. W. Assmann, "Computational Modeling of the Three-Dimensional Flow in a Metallic Stator Progressing Cavity Pump, Paper SPE-114110," in Proceedings of the SPE Progressing Cavity Pumps Conference, Houston, TX, USA, April 2008.

[17] E. E. Paladino, J. A. Lima, P. A. S. Pessoa, and R. F. C. Almeida, "Computational 3D simulation of the flow within progressing cavity pumps," in Proceedings of the 20th International Congress of Mechanical Engineering-COBEM, Gramado/RS, Brazil, November 2009.

[18] E. E. Paladino, J. A. Lima, P. A. S. Pessoa, and R. F. C. Almeida, "A computational model for the flow within rigid stator progressing cavity pumps," Journal of Petroleum Science and Engineering, vol. 78, no. 1, pp. 178-192, 2011.

[19] S. F. A. Andrade, J. V. Valério, and M. S. Carvalho, "Asymptotic model of the 3D flow in a progressing-cavity pump," SPE Journal, vol. 16, no. 2, pp. 451-462, 2011.

[20] J. Chen, H. Liu, F. S. Wang, G. C. Shi, G. Cao, and H. G. Wu, "Numerical prediction on volumetric efficiency of progressive cavity pump with fluidsolid interaction model," Journal of Petroleum Science \& Engineering, vol. 109, pp. 12-17, 2013.

[21] W. F. De Azevedo Victor, A. De Lima João, and E. Paladino Emilio, "A 3D transient model for the multiphase flow in a progressing-cavity pump," SPE Journal, vol. 21, no. 4, pp. 14581469, 2016. 
[22] A. Olivet, J. Gamboa, and F. Kenyery, "Experimental study of two-phase pumping in a progressive cavity pump metal to metal," in Proceedings of the SPE Annual Technical Conference and Exhibition, Paper SPE-77730, San Antonio, TX, USA, September 2002.

[23] J. Gamboa, A. Olivet, J. Iglesias, and P. Gonzalez, "Understanding the performance of a progressive cavity pump with a metallic stator," in Proceedings of the 23rd International Pump User Symposium, Los Teques, Venezuela, March 2002.

[24] J. Gamboa, A. Olivet, and S. Espin, "New approach for modeling progressive cavity pumps performance," Journal of Petroleum Technology, vol. 56, no. 5, pp. 51-53, 2003.

[25] P. A. S. Pessoa, E. E. Paladino, and J. A. Lima, "A simplified model for the flow in a progressive cavity pump," in Proceedings of the 20th International Congress of Mechanical EngineeringCOBEM, Gramado/RS, Brazil, November 2009.

[26] T. Nguyen, H. Tu, E. Al-Safran, and A. Saasen, "Simulation of single-phase liquid flow in Progressing Cavity Pump," Journal of Petroleum Science and Engineering, vol. 147, pp. 617-623, 2016.

[27] T. Nguyen, E. Al-Safran, A. Saasen, and O.-M. Nes, "Modeling the design and performance of progressing cavity pump using 3-D vector approach," Journal of Petroleum Science and Engineering, vol. 122, pp. 180-186, 2014.

[28] G. Vetter, W. Wirth, H. Korner, and S. Pregler, "Multiphase pumping with twin-screw pumps- understand and model hydrodynamics and hydroabrasive wear," in Proceedings of the 17th International Pump Users Symposium, Houston, Texas, USA, 2000

[29] J. N. Xu and W. T. Qu, Artificial lift technology of progressing cavity pump, Petroleum Industry Press, China, 2005.

[30] H. M. Martin, "Lubrication of gear teeth," Engineering Journal, vol. 102, no. 3, pp. 119-121, 1916.

[31] S. P. Zhang, Theory and application of elasto-hydrodynamic lubrication, Higher Education Press, China, 1995.

[32] J. D. Wei, Study and application of progressing cavity pump performance [PhD. Thesis], Daqing Petroleum Institute, Heilongjiang, China, 2007. 


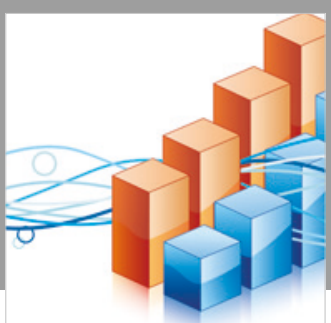

Advances in

Operations Research

\section{-n-m}
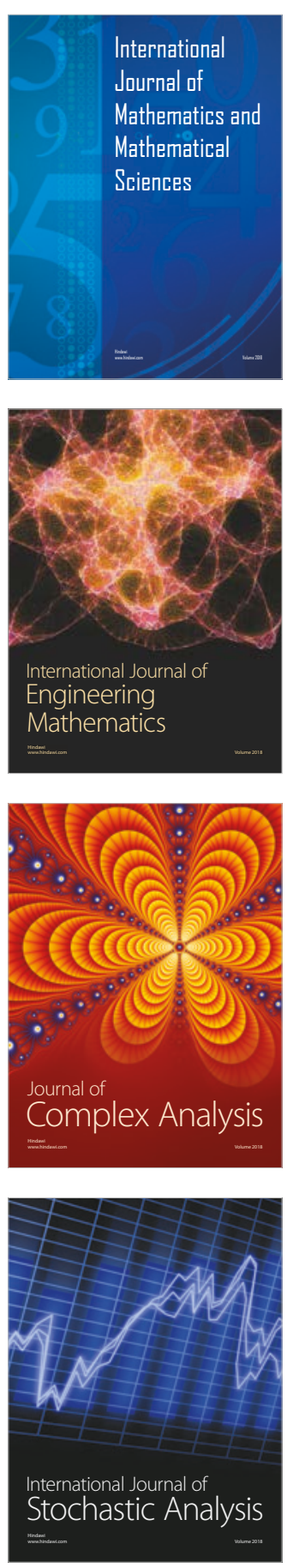
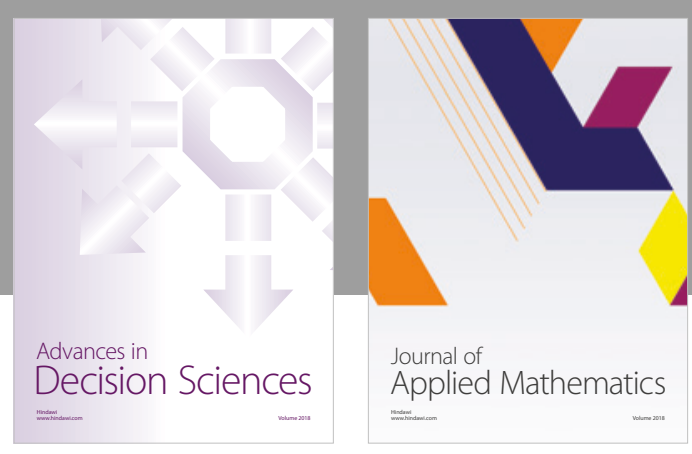

Journal of

Applied Mathematics
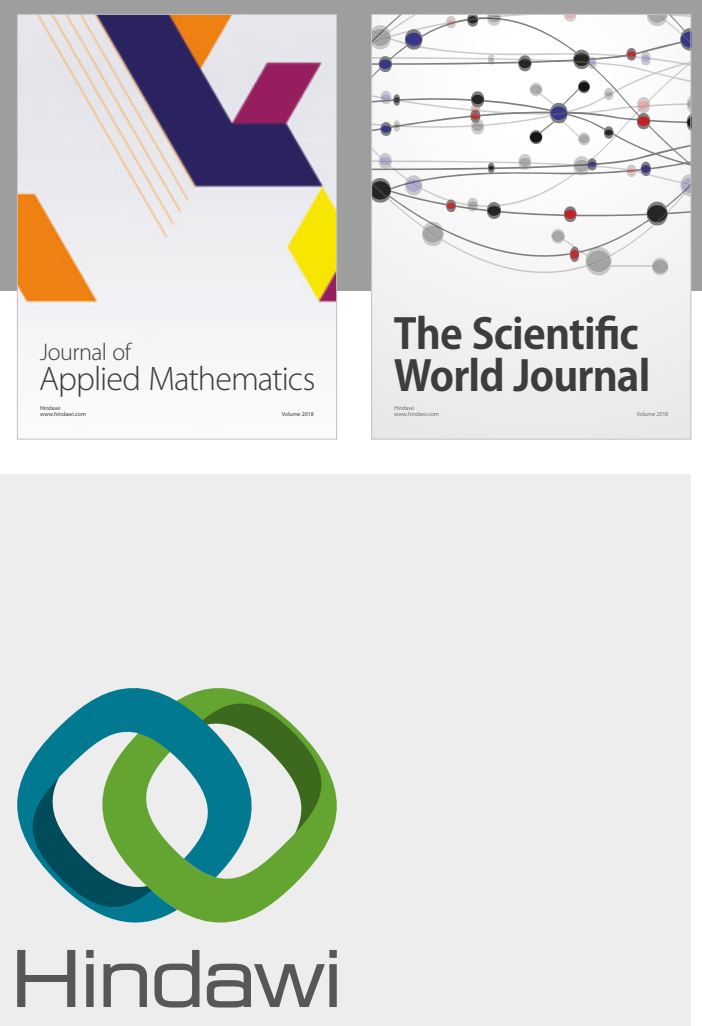

Submit your manuscripts at

www.hindawi.com

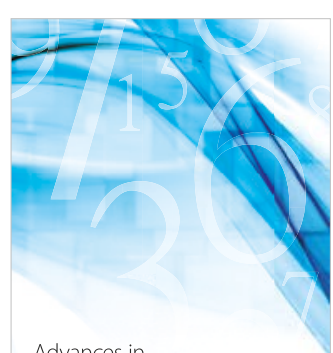

Advances in
Numerical Analysis
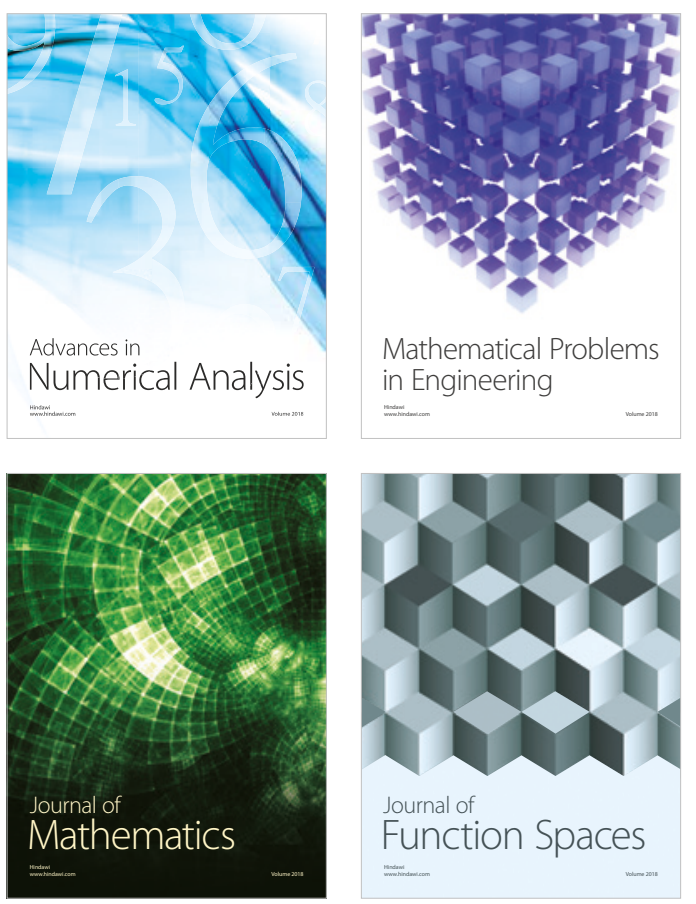

Mathematical Problems in Engineering

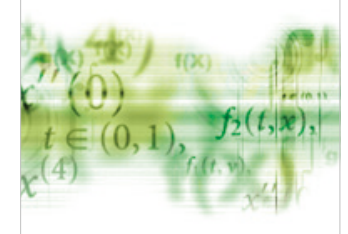

International Journal of

Differential Equations

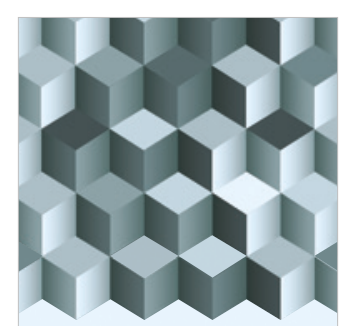

Journal of

Function Spaces

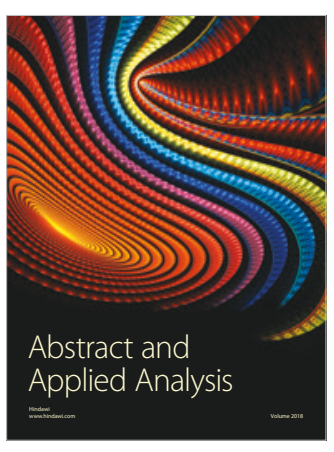

The Scientific

World Journal

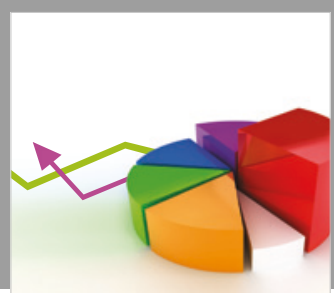

Journal of

Probability and Statistics
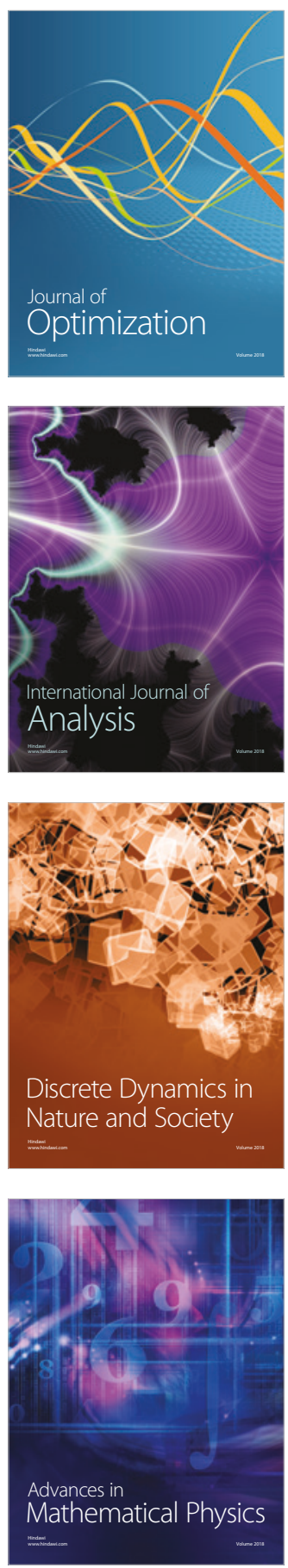